\title{
O ESTADO DO CONHECIMENTO SOBRE OS EGRESSOS DA EJA E SUA PERMANÊNCIA NA UNIVERSIDADE
}

\author{
Roberta de Jesus Muniz ${ }^{1}$ \\ Maria Hermínia Lage Fernandes Laffin ${ }^{2}$ \\ Sônia Maria Alves de Oliveira Reis ${ }^{3}$
}

\section{RESUMO}

O presente artigo situa um estudo do tipo estado do conhecimento com o objetivo de mapear o que se tem produzido acerca dos sujeitos egressos da Educação de Jovens e Adultos (EJA) no Ensino Superior em diferentes plataformas de socialização dos trabalhos acadêmicos, tais como Banco de Teses e Dissertações, artigos em periódicos e anais de eventos. O levantamento apresenta elementos de natureza teórica e permite conhecer o que já foi pesquisado e publicado sobre a inserção de alunos egressos da EJA no ensino superior, nos últimos 11 anos (2008-2018), período que marca a implementação de políticas públicas de inclusão das camadas populares no âmbito do ensino superior. Nos resultados da investigação foram identificados

\footnotetext{
${ }^{1}$ Mestra em Educação. Membro do dos grupos de pesquisa, Núcleo de Estudos, Pesquisa e Extensão Paulo Freire (Nepe- CNPq), Estudos e Pesquisas em Educação de Jovens e Adultos (Epeja). Membro do Fórum Municipal de Educação, atuando principalmente no monitoramento das metas do PNE 2014-2024 no eixo da EJA. ORCID: https://orcid.org/0000-0002-7912-3446. E-mail: roberta.uneb2016@gmail.com.

${ }^{2}$ Doutora em Educação. Pós-doutora pela Universidade do Estado da Bahia. Professora do Programa de Pós-graduação em Educação (PPGE) da Universidade Federal de Santa Catarina (UFSC). Coordenadora do Grupo de Estudos e Pesquisas em Educação de Jovens e Adultos Epeja/UFSC e da Pesquisa Nacional (CNPq) intitulada "Fundamentos e Autores Recorrentes do Campo da Educação de Jovens e Adultos no Brasil: a construção de um glossário eletrônico". Coeditora da Revista Internacional de EJA - Rieja (Uneb). ORCID: https://orcid.org/0000-0002-4562-308X. E-mail: herminialaffin@gmail.com.

${ }^{3}$ Doutora em Educação. Professora da Universidade do Estado da Bahia, graduação e cursos de especialização lato sensu. Professora externa do Programa de Pós-Graduação em Educação (PPGEd-Uesb). Coordenadora de área do Programa Institucional de bolsa de Iniciação à Docência (Pibid). Líder do Núcleo de Estudos Pesquisa e Extensão Educacional Paulo Freire Nepe-CNPq. Coordenadora do Doutorado InterinstitucionalDinter Uneb-UFMG. ORCID: https://orcid.org/0000-0003-0129-0719. E-mail: sonia_uneb@hotmail.com.
} 
vinte e quatro trabalhos que tratam dos egressos da Educação de Jovens e Adultos no ensino superior, debatendo os processos, trajetórias, os sentidos e seus sentimentos nesse nível de ensino, e apontam para a importância dessas políticas públicas para o acesso e a permanência na continuidade dos estudos. Em virtude disso, a criação desses programas pode possibilitar aos discentes não somente a qualificação para o mundo de trabalho, mas, também, o prosseguimento desses estudos, sendo essa uma forma de se encontrarem, se perceberem socialmente inseridos no âmbito da sociedade, já que são vistos, muitas vezes, com olhares estereotipados. Portanto, o estudo evidencia a necessidade de estudos acerca dos sujeitos advindos das camadas populares que ingressam no ensino superior.

Palavras-chave: Educação de Jovens e Adultos. Ensino Superior. Egressos da EJA.

\section{THE STATUS OF KNOWLEDGE ABOUT EJA GRADUATES AND THEIR STAY AT THE UNIVERSITY}

\section{ABSTRACT}

This paper presents a state of knowledge study aimed at mapping what has been produced about the Youth and Adult Education (EJA) graduates in Higher Education in different platforms for the publication of academic works, such as the Theses and Dissertations Bank, journal papers and conference proceedings. The survey presents theoretical elements and allows knowing what has been researched and published on the insertion of EJA graduates in higher education in the last 11 years (2008-2018), a period that marks the implementation of public policies for the inclusion of the lower classes in higher education. The results of the investigation pointed to twenty-four works dealing with graduates of Youth and Adult Education in higher education debating the processes, trajectories, meanings and feelings in higher education, and also point to the importance of these public policies for the access and the permanence at school. As a result, the creation of these programs can 
enable students not only to qualify for jobs, but also to pursue these studies, which is a way to meet people, to perceive themselves as socially inserted in the scope of society, since they are often seen with stereotyped looks. The study also highlights the need for studies on lower-class subjects who enter higher education.

Keywords: Youth and Adult Education. Higher Education. EJA graduates.

\section{EL ESTADO DEL CONOCIMIENTO DE LOS EGRESADOS DE EJA Y SU PERMANENCIA EN LA UNIVERSIDAD}

\section{RESUMEN}

El presente artículo sitúa un estudio del tipo estado del conocimiento con el objetivo de mapear lo producido sobre los jutetos egresados de la Educación de Jóvenes y Adultos (EJA) en la Educación Superior en diferentes plataformas de publicación de trabajos académicos, tales como el Banco de Tesis y Disertaciones, artículos en revistas y anales de eventos. La encuesta presenta elementos de naturaleza teórica y permite conocer lo investigado y publicado sobre la inserción de los egresados de EJA en la educación superior en los últimos 11 años (2008-2018), período que marca la implementación de políticas públicas para la inclusión de las capas populares en la educación superior. Los resultados de la investigación sinalizaron para veinticuatro trabajos que tratan con egresados de Educación de Jóvenes y Adultos en la educación superior debatiendo los procesos, trayectorias, significados y sentimientos en la educación superior, y apuntan para la importancia de estas políticas públicas para el acceso y la permanencia en la continuidad de los estudios. En virtud de eso, la creación de estos programas puede permitir a los estudiantes no solo la calificación para para el mundo laboral, sino también para continuar estos estudios, siendo esa una forma de encontrarse, de percibirse socialmente insertados en el ámbito de la sociedad, ya que son visto a menudo con miradas estereotipadas. Por tanto, el estudio evidencia la necesidad de estudios sobre los sujetos vindos de las capas populares que ingresan a la educación superior. 
Palabras clave: Educación de Jóvenes y Adultos. Enseñanza Superior. Graduados EJA.

\section{INTRODUÇÃO}

No campo da educação, percebe-se que, nos últimos anos, tornou-se "necessário" o levantamento bibliográfico de estudos que buscam mapear a produção de pesquisas científicas de determinadas áreas específicas que são publicadas em periódicos ou anais de eventos, para, a partir disso, construir o "estado do conhecimento" de estudos em torno de uma problemática à luz de diferentes aspectos conceituais e metodológicos que envolvem a educação que, segundo Romanowski e Ens (2006), o tipo de estudo permite a identificação dos temas que se destacam em detrimento de outros, bem como o acesso ao conhecimento já produzido, o que está sendo discutido, de que forma emerge a discussão e os apontamentos de possíveis lacunas do "objeto empírico" em investigação.

É nesse sentido que, motivadas por elementos de identificação temática e teórica, a discussão que se empreende procura apontar resultados do estudo bibliográfico em que foram analisadas pesquisas sobre a temática "a inserção de alunos egressos da Educação de Jovens e Adultos no Ensino Superior", no recorte temporal correspondente a 2008-2018. Tal periodicidade se justifica pelo fato de acreditarmos que, nesse período, a Educação de Jovens e Adultos esteve em constante debate, tanto político - com a implementação de importantes políticas públicas educacionais como apontam os estudos -, quanto acadêmico, uma vez que o primeiro trabalho publicado em relação ao objeto de estudo é identificado a partir do ano de 2008, como é demonstrado através do estado do conhecimento empreendido.

O mapeamento situado neste artigo apresenta elementos de natureza teórica que ressignifica a importância do estudo e as contribuições para o campo científico. Nesse sentido, reitera-se que este trabalho objetiva conhecer o que já foi pesquisado e publicado sobre a inserção de alunos egressos da EJA no ensino superior nos últimos 11 anos (2008-2018). 
A revisão bibliográfica das produções empreendidas foi realizada nos anais dos eventos científicos da Associação Nacional de Pós-Graduação e Pesquisa em Educação (Anped), no Banco de Teses e dissertações da Coordenação de Aperfeiçoamento de Pessoal de Nível Superior (Capes), na biblioteca virtual do Instituto Brasileiro de Informação em Ciência e Tecnologia (lbict), nos anais do Encontro Nacional de Didática e Práticas de Ensino (Endipe), no Portal de Periódicos da Coordenação de Aperfeiçoamento da Capes, no Google Acadêmico e nos anais do Encontro Internacional de Alfabetização e Educação de Jovens e Adultos (Alfaeeja).

No conjunto de trabalhos, foram identificadas 24 pesquisas, dentro do recorte temporal definido. As publicações se deram a partir do ano de 2008, com um trabalho publicado pela Capes no mesmo ano, um em 2013, três no ano de 2016 e três em 2018. Já no lbict foi localizado apenas um trabalho publicado no período em análise. Posto isso, no site do Google Acadêmico, as publicações variaram entre os anos de 2014 e 2018, com um trabalho publicado em 2014, um em 2015, quatro em 2016, dois em 2017 e um em 2018. Nos anais dos Encontros Nacionais de Didática (Endipe), foi identificado um trabalho publicado no ano de 2016 e dois em 2018. Já em relação aos anais da Associação Nacional de Pós-Graduação e Pesquisa em Educação (Anped), não foi localizado nenhum trabalho no período de 2008-2018. Nos anais dos Encontros Internacionais de Alfabetização e de Educação de Jovens e Adultos (Alfaeeja), encontramos dois trabalhos, ambos publicados em 2018, como se percebe na tabela 1.

Os dados da tabela 1 demonstram que, dos 24 trabalhos, houve um aumento nas produções acadêmicas a partir do ano de 2016, com oito publicações, e nove publicações no ano de 2018, o que evidencia que, a partir desse período, sucedeu uma ampliação nas produções acadêmicas em detrimento aos anos anteriores. 
Tabela 1 - Trabalhos publicados sobre a EJA 2008-2018.

\begin{tabular}{c|c|c|c|c|c|c}
\hline ANO & Capes & Ibict & $\begin{array}{c}\text { Google } \\
\text { Acadêmico }\end{array}$ & Endipe & Alfaeeja & $\begin{array}{c}\text { Publicações } \\
\text { por ano }\end{array}$ \\
\hline 2008 & 1 & - & - & - & - & 1 \\
\hline 2011 & - & 1 & - & - & - & 1 \\
\hline 2013 & 1 & - & - & - & - & 1 \\
\hline 2014 & - & - & 1 & - & - & 1 \\
\hline 2015 & - & - & 1 & - & - & 1 \\
\hline 2016 & 3 & - & 4 & 1 & - & 8 \\
\hline 2017 & - & - & 2 & - & - & 2 \\
\hline 2018 & 3 & - & 2 & 2 & 2 & 9 \\
\hline $\begin{array}{c}\text { Total de } \\
\text { produções } \\
\text { encontradas }\end{array}$ & 8 & 1 & 10 & 3 & 2 & 24 \\
\hline
\end{tabular}

Fonte: Elaboração das autoras a partir do levantamento bibliográfico (2020)

\section{DIRECIONANDO O OLHAR: A análise das produções bibliográficas no campo da EJA}

Para a realização da pesquisa de cunho exploratório, utilizamos como descritores as palavras-chave e, a partir disso, começamos as buscas pelas produções, iniciando pelas titulações e finalizando com a leitura dos resumos indicados pelos descritores: "egressos da Educação de Jovens e Adultos no ensino superior".

Para eleger descritores para as buscas, fizemos uso de vários termos, a saber: "a inserção de egresso da Educação de Jovens e Adultos no ensino superior", "egressos da EJA na universidade", "egressos da EJA no ensino superior", "egressos da Educação de Jovens e Adultos no ensino superior", "trajetória longevas de egresso da EJA", "egressos da educação de jovens e adultos", "EJA", "ensino superior", "universidade", no entanto, encontramos poucos trabalhos com esses descritores. Com base nisso, elegemos como descritor principal "egressos da Educação de Jovens e Adultos no ensino superior", pois encontramos um número maior de trabalhos. No 
entanto, a maior parte das produções não condizia com o objeto de estudo, uma vez que eram localizados estudos sobre a permanência dos egressos como atores sociais ${ }^{4}$ da Educação de Jovens e Adultos no ensino médio e a formação dos professores que atuam na Educação de Jovens e Adultos.

Diante disso, podemos afirmar que até o momento contamos com poucas produções acerca da temática em questão e as localizadas são recentes, pois verificamos que as produções se concentram nos anos de 2015 e 2016. Tal assertiva sobre a pouca produção acerca dessa temática já havia sido sinalizada por Cruz (2016), quando afirmou a quase ausência de pesquisas sobre a inserção de egressos da EJA no ensino superior.

$\mathrm{Na}$ análise dos anais das reuniões nacionais da Anped, entre os anos de 2008 (30 Reunião) a 2018 (38 ${ }^{a}$ Reunião) ${ }^{5}$, não encontramos nenhum trabalho referente ao tema "egressos da educação de Jovens e Adultos no ensino superior". Os trabalhos foram realizados nas modalidades de comunicação oral e pôsteres em todos os GTs, usando os descritores "egressos da Educação de Jovens e Adultos no ensino superior". Apenas no GT 18 - Educação de Pessoas Jovens e Adultas, encontramos dez trabalhos que

\footnotetext{
${ }^{4} \mathrm{O}$ conceito de atores sociais que adotamos é o mesmo definido por Martucelli (2007). De acordo com ele, as ciências sociais dispõem de um grande número de denominações para mencionar ao ser humano sob seus diferentes aspectos: "Sujeito", "ator", "agente", "personalidade", "pessoa", "identidade", "meu", "eu", "sou", "ego", "subjetividade". Mas a essência do relato sociológico sobre a modernidade implica a existência de um tipo particular de ator social. Um membro da comunidade, por exemplo, é sempre um ator social submetido à coletividade, pois ele é capaz de mudar seu entorno, dotado de intenções, de reflexões, de estratégias, compelido por contextos e múltiplos limites, e a interpretação, cuja conduta, além disso, oscila entre fatores anteriores ou que são bem projetivos. No entanto, o indivíduo não é somente um ator social. Representa, também, ainda que a sociologia tenha, às vezes, muita tendência em se esquecer disto dentro de seus sistemas metodológicos, uma definição normativa que informa em profundidade o caráter das práticas sociais. Portanto, o indivíduo é um ator empírico, próprio de toda coletividade humana, e é igualmente, e de maneira indissolúvel, na modernidade, um sujeito que se apoia em uma representação histórica.

${ }^{5}$ Realizamos as buscas no GT 2 - História da Educação, GT 3 - Movimentos Sociais e Educação, GT 4 - Didática, GT 5 - Estado e Política Educacional, GT 6- Educação Popular, GT 9 - Trabalho e Educação, GT10- Alfabetização, Leitura e Escrita, GT 11- Política da educação superior, GT 12- Currículo, GT 13- Educação Fundamental, GT 13- Sociologia da Educação, GT 15- Educação Especial, GT16- Educação e Comunicação GT 18Educação de Pessoas Jovens e Adultas.
} 
discutiam questões relacionadas à permanência dos estudantes da EJA nos Institutos Federais e no ensino médio, os significados da experiência escolar para o público jovem e adulto, bem como as políticas implementadas para a modalidade de ensino EJA nos últimos 20 anos. Não foi encontrado nenhum trabalho sobre "egressos da educação de jovens e adultos no ensino superior".

\section{O MAPEAMENTO NO BANCO DE TESES E DISSERTAÇÕES}

Iniciamos as pesquisas no site do Banco de Teses e Dissertações da Coordenação de Aperfeiçoamento de Pessoal de Nível Superior (Capes) utilizando os descritores "egressos da educação de jovens e adultos no ensino superior", no qual foram identificadas 987.207 publicações. Diante disso, fizemos o recorte temporal de 2008 a 2018, diminuindo, assim, o número de produções para 551.463. Ao delimitarmos a busca apenas em programas de mestrado e doutorado em educação, o número de produções reduziu para 18.834. De início, tomamos como base os títulos das produções, em seguida, selecionamos os trabalhos cujos temas apresentavam relevância para o nosso estudo e depois fizemos a leitura dos resumos. Percebendo que tais publicações discutiam a temática pesquisada, fizemos a leitura do texto por inteiro. Desse modo, localizamos no Banco de Teses e Dissertações da Capes oito trabalhos que discorrem sobre os estudantes jovens e adultos no ensino superior, sendo sete dissertações de mestrado e uma tese de doutorado em educação, conforme apresentado no quadro 1:

Quadro 1 - Produções Científicas do Banco de Teses e Dissertações da

Capes

\begin{tabular}{|c|c|c|c|c|}
\hline Autor & Título & Tipo & Instituição & Ano \\
\hline $\begin{array}{l}\text { BERTOLDI, } \\
\text { Adriana } \\
\text { Barufaldi }\end{array}$ & $\begin{array}{l}\text { Aprendizagem de } \\
\text { estudantes jovens e } \\
\text { adultos: um estudo em } \\
\text { cursos de educação } \\
\text { profissional de nível } \\
\text { médio e superior }\end{array}$ & Dissertação & $\begin{array}{l}\text { Universidade } \\
\text { do Vale do } \\
\text { Itajaí } \\
\text { (UNIVALI) }\end{array}$ & 2008 \\
\hline
\end{tabular}




\begin{tabular}{|c|c|c|c|c|}
\hline $\begin{array}{l}\text { FILHO, Rubem } \\
\text { Teixeira de } \\
\text { Jesus }\end{array}$ & $\begin{array}{l}\text { Contrariando a sina - da } \\
\text { educação de jovens e } \\
\text { adultos ao ensino } \\
\text { superior: escolaridades } \\
\text { exitosas de alunas } \\
\text { trabalhadoras }\end{array}$ & Dissertação & $\begin{array}{l}\text { Universidade } \\
\text { Federal de } \\
\text { Goiás }\end{array}$ & 2013 \\
\hline $\begin{array}{c}\text { ARAÚJO, } \\
\text { Adálcio } \\
\text { Carvalho de }\end{array}$ & $\begin{array}{l}\text { Egressos da EJA no } \\
\text { Curso de Administração } \\
\text { Pública EAD / FaPP / } \\
\text { UEMG: uma análise dos } \\
\text { fatores motivacionais da } \\
\text { interrupção e retomada } \\
\text { das trajetórias escolares } \\
\text { e a continuidade dos } \\
\text { estudos em nível } \\
\text { superior na EAD }\end{array}$ & Dissertação & $\begin{array}{l}\text { Universidade } \\
\text { do Estado de } \\
\text { Minas Gerais } \\
\text { (UEMG) }\end{array}$ & 2016 \\
\hline $\begin{array}{c}\text { BISINELLA, } \\
\text { Patrícia Borges } \\
\text { Gomes }\end{array}$ & $\begin{array}{l}\text { Trajetórias de Egressos } \\
\text { da EJA na Transição para } \\
\text { o Ensino Superior: um } \\
\text { estudo a partir do Prouni } \\
\text { (Caxias do Sul } 2005 \text { - } \\
\text { 2014) }\end{array}$ & Dissertação & $\begin{array}{l}\text { Universidade } \\
\text { de Caxias do } \\
\text { Sul (UCS) }\end{array}$ & 2016 \\
\hline $\begin{array}{l}\text { CRUZ, Neilton } \\
\text { Castro da }\end{array}$ & $\begin{array}{l}\text { "Esse ambiente não é } \\
\text { para todo mundo": as } \\
\text { condições de inserção e } \\
\text { de permanência de } \\
\text { egressos/as da EJA no } \\
\text { ensino superior público }\end{array}$ & Tese & $\begin{array}{l}\text { Universidade } \\
\text { Federal de } \\
\text { Minas Gerais } \\
\text { (UFMG) }\end{array}$ & 2016 \\
\hline $\begin{array}{c}\text { PEREIRA, } \\
\text { Diogo Rodrigo }\end{array}$ & $\begin{array}{l}\text { Trajetórias escolares, } \\
\text { condições de ingresso, } \\
\text { permanência e } \\
\text { conclusão dos egressos } \\
\text { da Educação de Jovens e } \\
\text { Adultos na Educação } \\
\text { Superior }\end{array}$ & Dissertação & $\begin{array}{l}\text { Universidade } \\
\text { Federal do } \\
\text { Maranhão } \\
\text { (UFMA) }\end{array}$ & 2018 \\
\hline $\begin{array}{c}\text { SANTOS, } \\
\text { Cintya Roberta } \\
\text { Oliveira dos }\end{array}$ & $\begin{array}{c}\text { Os sentidos sobre } \\
\text { Universidade Pública } \\
\text { para estudantes cotistas } \\
\text { egressos da Educação } \\
\text { de Jovens e Adultos: o } \\
\text { contexto da Faculdade } \\
\text { de Formação de } \\
\text { Professores / UERJ }\end{array}$ & Dissertação & $\begin{array}{l}\text { Universidade } \\
\text { do Estado do } \\
\text { Rio de Janeiro } \\
\text { (UERJ) }\end{array}$ & $2018 a$ \\
\hline
\end{tabular}




\begin{tabular}{|c|c|c|c|c|}
\hline $\begin{array}{c}\text { SANTOS, } \\
\text { Cleonice } \\
\text { Iracema } \\
\text { Graciano dos }\end{array}$ & $\begin{array}{l}\text { Sentidos e } \\
\text { (re)significados do } \\
\text { PROEJA na trajetória dos } \\
\text { egressos inseridos no } \\
\text { Ensino Superior }\end{array}$ & Dissertação & $\begin{array}{l}\text { Instituto } \\
\text { Politécnico do } \\
\text { Porto }\end{array}$ & $2018 b$ \\
\hline
\end{tabular}

Fonte: Elaborado pelas autoras com dados da pesquisa (2020).

Ressalta-se que, dentre as 18.834 produções, essas oito selecionadas discorrem sobre os egressos da Educação de Jovens e Adultos no ensino superior. Boa parte das pesquisas discute a Educação de Jovens e Adultos no contexto da formação de professores do ensino médio, da educação profissional, sobre a permanência e a evasão de alunos da EJA no ensino médio. $\mathrm{Na}$ medida em que íamos aprofundando nas pesquisas, os temas se distanciavam do que procurávamos e já não fazia mais menção alguma sobre os egressos da Educação de Jovens e Adultos no ensino superior. Contudo, tomando como base as buscas realizadas no Banco de Teses da Capes (quadro 1), podemos afirmar que é pequena a presença de estudos sobre a problemática estudada, já que foram localizados apenas 7 dissertações e uma tese, defendidas no período de 2008 a 2018.

De acordo com Cruz (2016), estudos que têm relação com a temática em questão podem trazer uma contribuição significativa ao campo de produção de conhecimento, sobretudo no que diz respeito à permanência de alunos egressos da EJA no processo de escolarização na universidade.

Essa consideração nos faz pensar que pouco se tem discutido sobre uma demanda tão específica da EJA, que é a inserção de seus sujeitos no ensino superior. Acreditamos que essa problemática deve ser discutida, afinal, tais sujeitos devem ser reconhecidos, assim como suas especificidades, mesmo sendo, em boa parte, minorias dentro da universidade pública.

Nesse contexto, a pesquisa de mestrado de Bertoldi (2008) teve como objetivo investigar os recursos que os estudantes jovens e adultos dizem utilizar para aprender, bem como as pautas interacionais propostas pelos docentes em contextos educacionais de educação profissional, nos níveis médio e superior. 
Já Jesus Filho (2013) traz como objetivo identificar quais fenômenos presentes nas trajetórias escolares e de vida desses alunos da EJA possibilitaram essa escolarização prolongada e exitosa, tão diferenciada, até 0 ingresso em um curso superior na Universidade Federal de Goiás. O autor conclui que, mesmo encontrando como base para uma escolarização de sucesso as relações interpessoais, a família e o trabalho, ficou evidente a necessidade da chamada "mobilização interior" dos sujeitos da pesquisa. Para o pesquisador, tal mobilização é muito importante para que uma escolaridade prolongada ocorra, uma vez que pode ser entendida como um conjunto de ações e posturas, resistentes aos aspectos negativos que tendem a impedir uma escolarização mais estendida, e que dependem primordialmente do próprio sujeito. É essa mobilização que vai dar ao indivíduo a condição de aceitar suas dificuldades, seus limites e sua própria condição de temporalidade, para superá-los e atingir seus objetivos.

A tese de doutorado de Cruz (2016) objetivou descrever e analisar em que medida se deu a inserção de egresso/a da EJA no ensino superior em instituição pública, de forma específica, em dois dos 24 Campi da Universidade do Estado da Bahia (Uneb). Cruz (2016b) evidencia nos achados da pesquisa a necessidade de uma maior interlocução entre a educação básica e a academia. Para o autor, por meio das narrativas, ficou perceptível que os egressos tinham poucas informações sobre os cursos ofertados pela Uneb. Entretanto, explica que, devido às experiências significativas e estimuladoras desenvolvidas pelos professores do ensino médio, foi possível a chegada dos alunos da EJA ao ensino superior público. Enfatiza que ao chegar à universidade os alunos que vieram da EJA, sobretudo as mulheres, sentiram-se empoderados.

A dissertação de mestrado de Araújo (2016) apresenta os fatores motivacionais para retomada dos estudos em nível superior de 14 estudantes egressos da EJA e matriculados no curso de Bacharelado em Administração Pública (EAD), da Universidade do Estado de Minas Gerais (UEMG).

Já Bisnella (2016), em sua dissertação, objetivou investigar as trajetórias e os fatores envolvidos no processo de transição de egressos da Educação de Jovens e Adultos (que ingressaram ou não) 
para o ensino superior, no município de Caxias do Sul- RS. Com os resultados da pesquisa, a autora percebeu que, apesar da existência de políticas públicas que favoreçam a permanência dos estudantes oriundos da EJA no ensino superior, é preciso aprimorá-las, pois, apesar de muitas iniciativas criadas, os resultados transparecem estar muito abaixo do esperado. As intervenções realizadas, que foram identificadas na pesquisa, apenas objetivaram o nivelamento dos estudos e não indicam a extensão de resultados esperados. Além do mais, os egressos da EJA são vistos com diferença pelas instituições de ensino superior e pela ideia de incapacidade sobre si mesmo diante dos demais estudantes advindos de formação regular.

A pesquisa de mestrado de Pereira (2018) objetivou analisar as trajetórias escolares, as condições de ingresso, permanência e conclusão dos estudos no ensino superior. As questões que o autor buscou discutir em seu texto foi principalmente sobre os dispositivos legais para implementação da EJA, abrangendo, nesse sentido, os aspectos culturais, educacionais, políticos e socioeconômico dos sujeitos atores da pesquisa, desde a escolarização inicial até a conclusão dos estudos na universidade. Como conclusão, o autor evidencia a insuficiência de políticas públicas para educação, tanto na esfera básica como superior, como principal elemento de permanência dos sujeitos da classe trabalhadora nos estudos. De acordo com esse pesquisador,

[...] é notória a exclusão precoce destes [sujeitos] nos processos de escolarização e, consequentemente, sua exploração sublinhada nas poucas e precárias oportunidades de emprego aliadas ao baixo salário [...] (PEREIRA, 2018, p.18).

Por isso é que se torna necessária uma política pública que garanta para além do acesso, a permanência em todos os segmentos educacionais e, assim, é preciso mais investimento na educação, para que os sujeitos das camadas menos favorecidas possam ter condições de almejar o ingresso e permanência no ensino superior. Para tanto, é imprescindível a implementação de políticas públicas que contemplem e incluem a EJA nesse cenário, já que em outras trajetórias apresentadas nos estudos anteriores foi a ponte de acesso 
para a universidade, além de carregar em sua essência, de certa maneira, a "única oportunidade ${ }^{6 "}$ que a camada popular encontra para dar continuidade aos estudos.

A pesquisa de Santos (2018a) busca analisar os sentidos que os sujeitos da EJA e ingressos pelo sistema de cotas atribuem ao acesso do ensino superior. A autora se preocupou em evidenciar os elementos constitutivos que subsidiou o acesso dos participantes do estudo à universidade pública no contexto da faculdade de formação de professores, da Universidade Estadual do Rio de Janeiro (UERJ). No decorrer de seu texto, a autora tece um diálogo acerca das políticas de ações afirmativas implementadas nas universidades públicas que oportuniza o acesso aos cursos superiores e nos instiga a indagar se essa forma de ampliação do acesso resulta efetivamente na democratização da educação, já que

[...] a universidade, enquanto uma instituição complexa de acesso desigual, acaba que também representando um projeto intencional em disputa, um campo de correlação de forças políticas, que busca instrumentalizar a educação para responder a determinados interesses [...] (SANTOS, 2018a, p.59).

Nesse sentido, evidencia esse processo como excludente, pois se torna um afunilamento seletivo social que, em sua própria estrutura, representa e ressalta a estrutura e desigualdade de classe, já que esse ingresso não garante as condições de permanência, tornando, de certa maneira, apenas um caminho para obtenção do diploma na universidade, com a conclusão do curso.

A dissertação de Santos (2018b) objetivou investigar os sentidos e (re)significados que os egressos do Programa Nacional de Integração da Educação Profissional com a Educação Básica (PROEJA) atribuíam à trajetória escolar. Além disso, trata-se de uma pesquisa

\footnotetext{
${ }^{6}$ Alguns pesquisadores tratam a Educação de Jovens e Adultos como a escola da segunda oportunidade, permitindo-nos percebê-la como a escola da única oportunidade e de direito, já que ela cumpre o papel de abarcar trajetórias não lineares, que a escola vista como "formal" não conseguiu abranger. Posicionamo-nos dessa maneira ao considerar que os estudos desenvolvidos na EJA foram a única possiblidade para muitos sujeitos de darem continuidade aos estudos e pensar em possibilidades de ingresso no ensino superior.
} 
de campo de abordagem qualitativa, que teve por participantes oito egressos dos Cursos Técnico em Informática e Técnico em Comércio, do Campus Júlio de Castilhos, que estavam matriculados em cursos superiores do Campus no segundo semestre de 2017. Como embasamento teórico, a autora utilizou dos conceitos da Andragogia ${ }^{7}$, a Educação de Jovens e Adultos e educação profissional para entender o fenômeno dos egressos do PROEJA na universidade, evidenciando em suas narrativas que "[...] o curso possibilitou delineamento da trajetória escolar no ensino superior quanto às mudanças positivas na forma de ser, de agir e de pensar [...]" (SANTOS, 2018b, p.4).

O levantamento no site da Biblioteca Digital Brasileira de Teses e Dissertações (BDTD) do Instituto Brasileiro de Informação em Ciência e Tecnologia (Ibict) foi realizado usando os descritores "egressos da Educação de Jovens e Adultos no ensino superior" que apontaram 58 resultados, no entanto, apenas duas dissertações se referem à temática em estudo, sendo que uma foi descartada, pois já havia sido localizada na plataforma da Capes, ficando apenas uma, que analisa as contribuições da educação à distância no curso superior presencial, a partir do olhar dos estudantes egressos da EJA, conforme mostra o quadro 2:

Quadro 2 - Produções Científicas dos trabalhos encontrados na BDTD e no lbict

\begin{tabular}{|l|c|c|c|}
\hline \multicolumn{1}{|c|}{ Autor } & Título & Instituição & Ano \\
\hline $\begin{array}{l}\text { CAMINHA, } \\
\text { Ivanete Saskoski }\end{array}$ & $\begin{array}{c}\text { Contribuições da EAD para o } \\
\text { ensino superior presencial na } \\
\text { visão de alunos egressos da } \\
\text { Educação de Jovens e Adultos. }\end{array}$ & $\begin{array}{c}\text { Universidade de } \\
\text { Taubaté (Unitau) }\end{array}$ & 2011 \\
\hline
\end{tabular}

Fonte: Elaborado pelas autoras com dados da pesquisa (2020).

\footnotetext{
${ }^{7} \mathrm{~A}$ andragogia refere-se à aprendizagem de adultos. A pedagogia e a andragogia ocupamse da aprendizagem de sujeitos em estágios de vida diferentes, o que demanda o uso de metodologias adequadas a cada etapa, fazendo com que a ação educativa, em cada grupo, ganhe contornos diferenciados. Para melhor compreensão do termo, indica-se a dissertação de Santos (2018b), analisada neste artigo.
} 


\section{OS ESTUDOS NO GOOGLE ACADÊMICO}

Em outra etapa, foi desenvolvida uma busca no Google Acadêmico, utilizando os mesmos descritores e o recorte temporal enunciado anteriormente. Foram encontrados dez trabalhos: quatro publicações em revistas, quatro publicações em anais de evento e duas monografias de graduação que tratavam da inserção de egressos da EJA no ensino superior, conforme apresentado no quadro 3:

Quadro 3 - Produções científicas dos trabalhos encontrados no Google Acadêmico

\begin{tabular}{|c|c|c|}
\hline Autor/instituição & Título & Publicação/ano \\
\hline $\begin{array}{l}\text { PAZ, Sebastiana (UFGD) } \\
\text { SANTOS, Maria de } \\
\text { Lourdes dos (UFGD). }\end{array}$ & $\begin{array}{c}\text { O Ingresso de Alunos } \\
\text { Egressos da EJA no Curso } \\
\text { de pedagogia da UFGD - } \\
\text { Turma de } 2013 \\
\end{array}$ & $\begin{array}{l}\text { Anais do } 8^{\circ} \text { Enepe UFGD - } \\
5^{\circ} \text { EPEX UEMS, Dourados } \\
\text { (MS) } 20 \text { a } 24 \text { de outubro de } \\
2014 .\end{array}$ \\
\hline SILVA, Neilton da (UFRB) & $\begin{array}{l}\text { Processo de afiliação de } \\
\text { egressos da EJA no ensino } \\
\text { superior: desafios e } \\
\text { propostas à docência } \\
\text { universitária } \\
\end{array}$ & $\begin{array}{l}\text { Revista Brasileira de } \\
\text { Educação de Jovens e } \\
\text { Adultos, v. 3, n. 5, 2015. }\end{array}$ \\
\hline $\begin{array}{l}\text { DIAS, Alder de Sousa } \\
\text { (Unifap) } \\
\text { OLIVEIRA, Júlia Milena da } \\
\text { Paixão (UEAP) } \\
\text { SANTOS, Manoel } \\
\text { Raimundo dos (UEAP) } \\
\text { SANTOS, Odite das Graças } \\
\text { Brilhante dos (UEAP) }\end{array}$ & $\begin{array}{l}\text { Mulheres egressas da EJA } \\
\text { na universidade: entre } \\
\text { intempéries, sonhos } \\
\text { possíveis e inéditos viáveis }\end{array}$ & $\begin{array}{l}\text { Revista Atos de Pesquisa } \\
\text { em Educação. Blumenau - } \\
\text { v. 11, n. 2, p. 444-467 } \\
\text { ago./nov. 2016. }\end{array}$ \\
\hline $\begin{array}{l}\text { NERES, Celi Corrêa (UEMS) } \\
\text { MILAN, Elizonir Ferreira } \\
\text { Arcanjo (UEMS) } \\
\text { SILVA, Maria Lourdes S. } \\
\text { (UEMS) }\end{array}$ & $\begin{array}{l}\text { Alunos da Educação de } \\
\text { Jovens e Adultos: a } \\
\text { recente trilha para a } \\
\text { educação superior }\end{array}$ & $\begin{array}{l}\text { Plurais - } \quad \text { Revista } \\
\text { Multidisciplinar. Salvador, } \\
\text { v. 1, n. 2, p. 44-57, abr./ago. } \\
2016 .\end{array}$ \\
\hline $\begin{array}{l}\text { SANTOS, Geovânia Lúcia } \\
\text { dos (UFMG) }\end{array}$ & $\begin{array}{l}\text { Educação Superior ainda } \\
\text { que tardia: impactos e } \\
\text { efeitos da educação } \\
\text { superior entre adultos } \\
\text { egressos da EJA }\end{array}$ & $\begin{array}{l}\text { Anais da } 6^{a} \text { Conferência } \\
\text { Forges. } \\
\text { Estadual de Campinersidade } \\
28 \text { a } 30 \text { de novembro de } \\
2016 \text {. }\end{array}$ \\
\hline
\end{tabular}




\begin{tabular}{|c|c|c|}
\hline $\begin{array}{l}\text { NASCIMENTO, Maria } \\
\text { Rongirlene Oliveira do } \\
\text { (UEVA). }\end{array}$ & $\begin{array}{l}\text { Inclusão dos estudantes } \\
\text { da Educação de Jovens e } \\
\text { Adultos } \\
\text { no ensino superior: } \\
\text { desafios e percepções }\end{array}$ & $\begin{array}{l}\text { Anais do II Congresso } \\
\text { Internacional de Educação } \\
\text { Inclusiva - CINTEDI e a II } \\
\text { Jornada Chilena Brasileira } \\
\text { sobre Educação Inclusiva } \\
\text { realizada em Campina } \\
\text { Grande (PB) no período de } \\
16 \text { a } 18 \text { de novembro de } \\
2016 \text {. }\end{array}$ \\
\hline $\begin{array}{l}\text { BISPO, Francineide de } \\
\text { Sousa (UFPI) } \\
\text { LIRA, João Antônio de } \\
\text { Sousa (UFPI) }\end{array}$ & $\begin{array}{l}\text { Trajetórias de egressos da } \\
\text { EJA no ensino superior: } \\
\text { desafios e perspectivas }\end{array}$ & $\begin{array}{l}\text { Anais do IV } \\
\text { CONGRESSO NACIONAL } \\
\text { DE EDUCAÇÃO. A } \\
\text { Educação brasileira: } \\
\text { desafios na atualidade. } \\
\begin{array}{l}\text { João Pessoa - PB, } 15 \text { a } 18 \\
\text { de novembro de } 2017 .\end{array}\end{array}$ \\
\hline $\begin{array}{l}\text { FREITAS, Adnilsa Avelino } \\
\text { de (UERN) }\end{array}$ & $\begin{array}{l}\text { O sucesso do aluno da EJA } \\
\text { e seu ingresso no ensino } \\
\text { superior }\end{array}$ & $\begin{array}{l}\text { Monografia (Graduação } \\
\text { em Pedagogia) } \\
\text { Universidade do Estado do } \\
\text { Rio Grande do Norte, } 2017 .\end{array}$ \\
\hline $\begin{array}{l}\text { ROSA, Caroline de Moura. } \\
\text { SANT'ANNA, Sita Mara } \\
\text { Lopes. STRAMARE, } \\
\text { Odilon Antônio }\end{array}$ & $\begin{array}{l}\text { Sentidos de qualidade: } \\
\text { vozes de professores e } \\
\text { estudantes egressos da } \\
\text { EJA no ensino superior }\end{array}$ & $\begin{array}{l}\text { Revista de Educação } \\
\text { Pública. v. } 15 \text { (2018). }\end{array}$ \\
\hline DOTTA, Carla Luz Salaibb & $\begin{array}{l}\text { Da educação básica a } \\
\text { universidade: Alunos da } \\
\text { LEDOC oriundos da EJA }\end{array}$ & $\begin{array}{l}\text { Monografia, (Graduação } \\
\text { em Educação do Campo) } \\
\text { Universidade Federal do } \\
\text { Rio Grande do Sul (2018). }\end{array}$ \\
\hline
\end{tabular}

Fonte: Elaborado pelas autoras com dados da pesquisa (2020).

Os trabalhos identificados no Google Acadêmico (quadro 3) nos instigam a pensar que a "demografização" do ensino superior público brasileiro, aliado ao processo de expansão das universidades públicas nos últimos 20 anos, contribuiu para que os jovens e adultos acessassem a formação universitária, ainda que tardia. O termo "demografização" utilizado refere-se ao crescimento quantitativo das instituições de ensino superior que, de acordo com Sato (2018), é o aumento de chances do acesso à escolarização para todos os níveis sociais.

O conjunto dos trabalhos revela que o processo de acesso e a permanência dos alunos egressos da EJA no ensino superior têm sido permeados de obstáculos e incertezas. Há desafios ligados a questões pessoais, como autoestima e motivação e, além disso, 
ligados a fatores como a distância entre casa e escola, conciliação do tempo para trabalho e estudo, fragmentação do conhecimento e currículo desarticulado com seus interesses pessoais, conhecimentos prévios insuficientes, falta de tempo para os estudos, dentre outros. No entanto, os alunos egressos da EJA sinalizam que é possível transformar a história de escolarização desses educandos e tornar o acesso e a permanência no ensino superior um sonho inédito viável.

Nesse contexto, os autores evidenciam a necessidade de se pensar estratégias para a acolhida dos alunos egressos da EJA nos cursos superiores e a prática profissional dos docentes universitários, face à condição dos novos estudantes que chegam à universidade. Esse fenômeno emergente requer, portanto, providências institucionais, com vistas à garantia da permanência, da qualidade das aprendizagens e das vivências acadêmicas dos estudantes.

O artigo de Silva (2015) tem como foco principal problematizar a afiliação de egressos da EJA no ensino superior, na perspectiva de sinalizar os desafios à docência universitária pública. O autor salienta que a chegada dos alunos da EJA à universidade pública foi um processo tardio, e que há a necessidade de repensar a prática docente, pois são muitos desafios encontrados por professores e alunos ao se deparar com os diversos na academia.

Diante do novo perfil de ingressantes no ensino superior, nas IES públicas, os docentes universitários se veem diante da tarefa de mobilizar seus saberes e suas competências para ensinar, fazendo frente às dificuldades apresentadas pelos estudantes jovens e adultos, visando à sua superação através de ações estratégicas que favoreçam a construção do conhecimento com base na realidade concreta, no diálogo e nos interesses dos sujeitos. Inegavelmente, os primeiros passos a serem dados passam pela valorização da pessoa do estudante, pelo respeito e conhecimento da sua história e pelas aprendizagens da vida, que forjaram as experiências e modos de compreensão, que os fizeram chegar à universidade (SILVA, 2015, p.140).

Partindo desse pressuposto, é possível perceber que, para ser professor universitário, deve-se estar preparado não somente para o 
ensino, a pesquisa e a extensão, mas, também, para saber ouvir, entender a trajetória de vida dos sujeitos que ali estão e, principalmente, conhecer as especificidades de cada um, uma vez que a aprendizagem se torna mais fluida e prazerosa, quando o que está sendo ensinado abrange a realidade vivida, ou é de interesse do educando, como nos é apontado por Freire (1999).

Dias e outros (2016) apresentam o perfil sociocultural e socioeducacional de mulheres egressas da EJA e discentes de uma universidade pública, e analisam as relações entre as subjetividades dessas mulheres e os condicionantes pelos quais passaram. As interlocutoras desse estudo foram quatro mulheres alunas da universidade pública, advindas da Educação de Jovens e Adultos. Tomaram como principais referências para esse estudo algumas obras de Paulo Freire, como: Pedagogia do Oprimido, Pedagogia da Esperança, Pedagogia da Tolerância, Pedagogia dos Sonhos Possíveis, e outras. O estudo aponta para a necessidade de criação de políticas públicas educacionais e práticas de ensino que atendam às especificidades das mulheres egressas da EJA que conseguem chegar ao ensino superior e as reconheçam enquanto sujeito de direito.

O artigo de Bispo e Lira (2017) trata da apresentação dos dados obtidos no trabalho de conclusão de curso de licenciatura em Pedagogia, realizado na Universidade Federal do Piauí (UFPI), com quatro estudantes que tiveram seus percursos de escolarização entrelaçados na EJA. O objetivo principal da investigação foi de analisar as vivências de estudantes universitários egressos da EJA que tiveram experiências singulares na modalidade de ensino e conseguiram o ingresso no ensino superior; e a partir da inclusão na universidade, desmistificar a visão estereotipada que caracteriza a Educação de Jovens e Adultos como compensatória e segunda oportunidade. Tal assertiva, que envolve o objeto principal de investigação, de acordo com a autora, é o de que a educação deve refletir sobre a realidade dos seus sujeitos; e a EJA, em seu processo histórico, tem desenvolvido este papel, uma vez que promove a tecitura entre os dois mundos que não são distintos um do outro. $O$ mundo do trabalho e dos estudos, para uma possível inserção social. 
Em seu artigo, Rosa, Sant'anna e Stramare (2018) se incumbiram de "dar voz" aos estudantes e professores egressos da EJA na universidade, partindo dos estudos já realizados por Gadotti (2003), Gentili (1999) e Marques (2000). Como resultados, sobressaíram nas falas dos docentes a perspectiva neoliberal da educação, nesse sentido, voltada ao ingresso no mercado de trabalho. Já na visão dos discentes, esta foi frisada como uma possível saída para o reconhecimento social, além da promoção de melhores oportunidades de trabalho "mais bem pago".

O outro trabalho encontrado, de autoria de Dotta (2018), teve como foco os estudantes oriundos da EJA, egressos do ensino superior, especificamente do curso de licenciatura em Educação do Campo, destacando, portanto, as expectativas, sentimentos e possíveis dificuldades em relação aos conteúdos e à dinâmica de ensino dos cursos superiores. O estudo foi desenvolvido tendo como princípio o fato de a pesquisadora ter tido sua trajetória na Educação de Jovens e Adultos e, no momento de investigação, cursar a Licenciatura em Educação do Campo, que, para ela,

A Educação de Jovens e Adultos, a Educação do Campo, vêm ganhado espaço na luta em favor de seus representantes, os sujeitos do campo vinculados às conquistas estabelecidas através dos movimentos sociais. A Educação do Campo e a de Jovens e Adultos representa dois marcos importantes na luta pelo acesso e permanência com qualidade na educação. A resistência e organização dos movimentos sociais, de educadores, de instituições educacionais, intelectuais e de estudantes, [...] têm conquistado avanços significativos na garantia do direito à educação (DOTTA, 2018, p.14).

É nesse sentido que reafirmamos a importância da implementação de políticas públicas educacionais e sociais que garantam o acesso e a permanência dos sujeitos pobres nos cursos superiores, e, além disso, repensar essas duas modalidades de ensino para além de uma nova oportunidade e elevação de escolaridade na educação básica. Ademais, ao conseguirem contrariar as estatísticas 
e ingressar na universidade, serem percebidos como sujeitos reais e históricos que tiveram suas trajetórias interrompidas no decorrer da educação básica e que, por isso, faz-se necessária uma educação que dialogue plenamente com a realidade de seu público.

\section{O LEVANTAMENTO NO ENCONTRO NACIONAL DE DIDÁTICA E PRÁTICAS DE ENSINO (ENDIPE)}

Isso posto, no mapeamento realizado nos Anais do Encontro Nacional de Didática e Práticas de Ensino (Endipe), foram situados 22 trabalhos relacionados à Educação de Jovens e Adultos. No entanto, a maior parte deles versa sobre as políticas públicas educacionais brasileiras para a EJA e o ensino superior, e formação continuada para professores, sendo que apenas três discutem a EJA no ensino superior, como mostra o quadro 4:

Quadro 4 - Produções científicas dos trabalhos encontrados nos Anais do Endipe

\begin{tabular}{|c|c|c|}
\hline Autor/instituição & Título & Edição/ano \\
\hline $\begin{array}{l}\text { CRUZ, Neilton } \\
\text { Castro da, (UFMG) } \\
\text { EITERER, Carmem Lúcia } \\
\text { (UFMG) }\end{array}$ & $\begin{array}{l}\text { A Inserção de Egresso/a da EJA no } \\
\text { Ensino Superior Público na Bahia: a } \\
\text { significativa contribuição do/a } \\
\text { professor/a da educação básica na } \\
\text { trajetória escolar desse sujeito }\end{array}$ & $\begin{array}{l}\text { Anais do XVIII Endipe. } \\
\text { Universidade Federal } \\
\text { do Mato Grosso, } \\
\text { Cuiabá-MT, } 23 \text { a } 26 \text { de } \\
\text { agosto de } 2016 .\end{array}$ \\
\hline $\begin{array}{l}\text { MUNIZ, Roberta de } \\
\text { Jesus Muniz (UFSC) } \\
\text { REIS, Sônia Maria Alves } \\
\text { de Oliveira Reis (Uneb). }\end{array}$ & $\begin{array}{l}\text { A Travessia da Educação de Jovens } \\
\text { e Adultos para a Universidade: "As } \\
\text { razões do improvável" }\end{array}$ & $\begin{array}{l}\text { Anais do XIX Endipe. } \\
\text { Universidade Federal } \\
\text { da Bahia, Salvador- } \\
2018 \text {. }\end{array}$ \\
\hline $\begin{array}{l}\text { CRUZ, Neilton Castro } \\
\text { da (UFMG) } \\
\text { REIS, Sônia Maria Alves } \\
\text { de Oliveira (Uneb) }\end{array}$ & $\begin{array}{l}\text { "Vim da EJA com muito orgulho": A } \\
\text { inserção de egressos/as da } \\
\text { Educação de Jovens e Adultos na } \\
\text { Universidade do Estado da Bahia }\end{array}$ & $\begin{array}{l}\text { Anais do XIX Endipe. } \\
\text { Universidade Federal } \\
\text { da Bahia, Salvador- } \\
2018 .\end{array}$ \\
\hline
\end{tabular}

Fonte: Elaborado pelas autoras com dados da pesquisa (2020).

O artigo de Muniz e Reis (2018a) trata-se de um recorte do trabalho de conclusão de curso de licenciatura em Pedagogia, realizado na Universidade do Estado da Bahia, Campus XII de Guanambi-BA, com sujeitos que tiveram seus percursos formativos 
na EJA e fizeram a travessia para os cursos superiores. Teve como participantes nove sujeitos, que tiveram de superar obstáculos em suas trajetórias e, apesar das estatísticas anteriormente sinalizadas por Lahire $(2002,2004)$ e Portes $(1993,2001)$, conseguiram trajetórias longevas e adentraram na universidade. Analisam, portanto, as condições do acesso e permanência desses sujeitos no ensino superior. Além disso, outros teóricos que subsidiaram as discussões abrangidas foram Arroyo (2012) e Cruz e Eiterer (2016). e o estudo sinalizou a necessidade de estudos teóricos que discutam acerca das condições de permanência dos sujeitos das camadas populares no ensino superior público e a insuficiência das políticas públicas de permanência estudantil.

Nesse contexto, o artigo de Cruz e Reis (2018) buscou analisar como se deu a inserção e permanência de egressos da EJA no ensino superior à luz de três conceitos básicos: Mobilização (CHARLOT, 2000), Estratégia (BOURDIEU, 2004) e Suporte (MARTUCELLI, 2007), que resultaram da pesquisa de doutorado realizada em 2016 na Universidade Federal de Minas Gerais - UFMG. A pesquisa foi realizada com oito pessoas, sendo cinco de sexo feminino e três do sexo masculino, em quatro cursos de licenciatura, em dois dos 24 Campi da Universidade do Estado da Bahia - Uneb.

\section{PRODUÇÕES CIENTÍFICAS DOS TRABALHOS ENCONTRADOS NOS ANAIS DOS ALFAEEJA}

Fizemos a mesma busca nos Anais do Alfaeeja ${ }^{8}$ em nove eixos temáticos: I - Currículo na Educação de Jovens e Adultos; II - Sujeitos da Educação de Jovens e Adultos; III - Alfabetização e Letramento na Educação de Jovens e Adultos; IV - Pesquisa em Educação de Jovens e Adultos; V - Formação de Professores na EJA; VI - EJA, Movimentos Sociais e Direitos Humanos; VII - EJA na Perspectiva do Mundo do Trabalho; VIII - Políticas Públicas e Gestão Educacional e Escolar na EJA; e IV - Múltiplas Linguagens, Tecnologia da Informação e da Comunicação na EJA: Perspectivas Teórico-Metodológica. Vale ressaltar que, excepcionalmente, nesse levantamento, não fizemos

\footnotetext{
${ }^{8}$ Não foram localizados trabalhos sobre os egressos nas outras edições.
} 
uso dos descritores, pois os anais encontram-se organizados de forma sequenciada, em arquivo formatado e, assim, houve a necessidade de verificar todos os trabalhos.

Encontramos dois trabalhos referentes ao tema "egressos da EJA no ensino superior". Um foi localizado no eixo II, na edição do evento realizada em Porto Alegre; e outro foi localizado no eixo IV, na pré-abertura do evento realizado em Salvador.

Quadro 5 - Produções científicas dos trabalhos encontrados nos Anais do Alfaeeja

\begin{tabular}{|c|c|c|}
\hline Autor/instituição & Título & Publicação/ano \\
\hline $\begin{array}{l}\text { ALMANSA, Jordy Otaran. } \\
\text { (PUCRS) } \\
\text { FRAGA, Ingrid (PUCRS). } \\
\text { LA FARE, Mônica de } \\
\text { (PUCRS). }\end{array}$ & $\begin{array}{l}\text { Os egressos/estudantes da } \\
\text { EJA do Ensino médio e o } \\
\text { acesso à Universidade: } \\
\text { análise dos microdados do } \\
\text { ENEM }\end{array}$ & $\begin{array}{lr}\text { Anais do V } & \text { Encontro } \\
\text { Internacional } & \text { de } \\
\text { Alfabetização de Jovens } \\
\text { e Adultos - Alfaeeja } \\
\text { Universidade Federal do } \\
\text { Rio Grande do Sul, Porto } \\
\text { Alegre- } 2018 \text {. }\end{array}$ \\
\hline $\begin{array}{l}\text { MUNIZ, Roberta de Jesus } \\
\text { Muniz (UFSC) } \\
\text { REIS, Sônia Maria Alves } \\
\text { de Oliveira Reis (Uneb). }\end{array}$ & $\begin{array}{l}\text { Da EJA para a universidade: o } \\
\text { compasso entre o acesso e as } \\
\text { singularidades dos sujeitos }\end{array}$ & $\begin{array}{lr}\text { Anais do V } & \text { Encontro } \\
\text { Internacional } & \text { de } \\
\text { Alfabetização de Jovens } \\
\text { e Adultos - Alfaeeja } \\
\text { Universidade do Estado } \\
\text { da Bahia, Salvador- } 2018 .\end{array}$ \\
\hline
\end{tabular}

Fonte: Elaborado pelas autoras com dados da pesquisa (2019).

O artigo de autoria de Almansa, Fraga e La Fare (2018) discorre sobre os egressos da EJA que tiveram o acesso à universidade através do Enem, bem como analisa as trajetórias escolares e as estratégias de estudantes do último ano do ensino médio da EJA para acessar a esse espaço social, levando em consideração as transformações ocorridas no ensino superior brasileiro a partir da década de 1990.

O principal teórico que subsidiou a discussão foi Pierre Bourdieu, a partir do Estruturalismo Construtivista, relacionado, nesse sentido, ao conceito de trajetória, agente, campo e habitus, que, de acordo com o autor, a partir dessa perspectiva, a noção de trajetória é entendida como "[...] uma série de posições sucessivamente ocupadas por um mesmo agente (ou um mesmo grupo) num espaço em movimento e submetido a incessantes transformações [...]" 
(BOURDIEU, 1997, pp.81-82), e sua elaboração é acompanhada pela crítica ao uso de histórias de vida e abordagens biográficas na pesquisa social, baseada no uso de relatos de uma vida como uma série de ações lógicas e lineares que se sucedem e que se centralizam nas ações do próprio indivíduo.

Do ponto de vista metodológico, utilizou-se de dados qualitativos, elaborados a partir da realização de entrevistas semiestruturadas com estudantes de escolas públicas e de cursos pré-vestibulares populares, no período de 2015-2017, que participaram do Enem, considerado como uma das formas de acesso à universidade.

O estudo é sinalizado pelos autores como um importante espaço de aproximação entre a educação básica, com ênfase na EJA. A universidade, ainda, é considerada como um espaço elitizado e são poucos os que conseguem ingressar e permanecer nos estudos,

[...] questão que necessita ser potencializada e aprofundada para garantir o direito à educação para o conjunto da população e para produzir avanços na superação das históricas desigualdades sociais que também se identificam no sistema educacional [...]. (ALMANSA; FRAGA; LA FARE, 2018, p. 80)

Nesse contexto, Muniz e Reis (2018a, 2018b) colaboram com a discussão das autoras, já que também apresentam dados de um estudo realizado com os estudantes da Educação de Jovens e Adultos no ensino superior público da Uneb/DEDC XII, dado que verifica o ingresso de $48 \%$ de seu público via Enem.

Os dados revelados pelas autoras evidenciam, de forma tímida, a presença de estudantes das camadas populares e, nesse sentido, egressos da EJA no sistema universitário, já que esse não é um ambiente para todos. Assim, visto pela lógica da meritocracia,

[...] o acesso é para poucos [...] os sujeitos que ousam ingressar e permanecer na universidade, principalmente os sujeitos egressos da EJA são minorias, pois a academia é criada para sujeitos financeiramente bem, que tiveram a trajetória 
perfeita [...] É muita ousadia um aluno da EJA estar na academia. (MUNIZ; REIS, 2018a, p. 69).

De acordo com essas autoras, são poucos os sujeitos das camadas humildes que conseguem ingressar e permanecer nos estudos, uma vez que estes necessitam indagar sua própria história para dar sentido as suas trajetórias humanas, enquanto seres históricos e sociais, dada a própria condição de ser humano em um contexto ambivalente a sua realidade.

Ainda Muniz e Reis (2018a, 2018b) sinalizam para a necessidade de se pensar em políticas públicas educacionais que contemplem para além do acesso à permanência, dado que anteriormente foi sinalizado por Oliveira (2014, p. 33), ao afirmar que as políticas educacionais como, por exemplo, o "[...] Enem não solucionará [...] os problemas estruturais, como a falta de vagas para o acesso de todos os candidatos à educação superior [...]", todavia, se torna uma política de Estado importante para se pensar na ampliação de acesso e permanência nos estudos. Outrossim, destacam que são escassas as pesquisas que discutem sobre os egressos da Educação de Jovens e Adultos no ensino superior.

Posto isso, revela-se a importância de conhecer as produções científicas brasileiras (artigos, dissertações e teses) sobre a inserção dos egressos da EJA na universidade, publicada no período de 20082018.

\section{CONSIDERAÇÕES FINAIS}

Ao situar o estado do conhecimento, foi possível perceber que, no campo empírico, ainda são poucas as produções que discorrem sobre o tema em questão. Nos resultados situamos que as produções científicas tratam dos egressos da Educação de Jovens e Adultos no ensino superior sobre os processos, trajetórias, sentidos e sentimentos, e também as políticas públicas para o acesso e a permanência no ensino superior público, sempre tendo os sujeitos como foco principal. Tais políticas públicas de inclusão e permanência para estudantes, particularmente as de ações afirmativas e de bolsas de permanência, pensadas para o ensino superior, se dão a partir do 
século XXI, quando o Brasil perpassa por um cenário político histórico, no âmbito da educação, especificamente no contexto do governo do Partido dos Trabalhadores (PT), com o presidente da República Luís Inácio Lula da Silva (2003-2006) - (2006-2011) com continuidade do governo da presidenta Dilma Vana Roussef (20112016). Os estudos analisados apontam para os impactos positivos desses programas e políticas na trajetória dos egressos da EJA.

As investigações analisadas discorrem também sobre a importância da criação de políticas públicas que garantam a continuidade dos estudos dos alunos da EJA, uma vez que as que já existem abrangem apenas o acesso à educação básica. Em virtude disso, a criação desses programas pode possibilitar aos discentes não somente a qualificação para o mundo do trabalho, mas, também, o prosseguimento desses estudos, sendo essa uma forma de se encontrarem, se perceberem socialmente inseridos no âmbito da sociedade, já que são vistos, muitas vezes, com olhares estereotipados.

É importante destacar que as pesquisas são de cunho qualitativo e, como instrumento de coleta de dados, em sua maioria, utilizaram a entrevista narrativa. Predominantemente, a escolha se deu por entender que, para compreender a experiência de vida dos egressos da EJA, cada um deveria narrar sua história de vida escolar, abrangendo desde o ingresso na escola até a condição de estudante de nível superior.

Todos os estudos são relevantes, visto que, diante da investigação realizada, pode se reiterar a pequena quantidade de produções existentes que discutem a temática. Dessa maneira, ficou perceptível a necessidade de pesquisas sobre os egressos da Educação de Jovens e Adultos no ensino superior público, pois esses diversos atores sociais não podem e nem poderão ser esquecidos, devem ser ouvidos e terem sua trajetória escolar reconhecida dentro da academia.

Além disso, é preciso que os docentes conheçam e levem em conta as suas especificidades, já que esses vêm de um percurso escolar prolongado e, ao mesmo tempo, cheio de barreiras e com muitos sonhos a realizar. Após a construção deste estado do conhecimento, os resultados nos apontam para a necessidade de 
estudos acerca dos sujeitos advindos das camadas populares que ingressam no ensino superior.

\section{REFERÊNCIAS}

ALMANSA, Jordy Otaran. FRAGA, Ingrid. LA FARE, Mônica de (PUCRS). Os egressos/estudantes da EJA do Ensino médio e o acesso à Universidade: análise dos microdados do ENEM. In: ENCONTRO INTERNACIONAL DE ALFABETIZAÇÃO DE JOVENS E ADULTOS - Alfaeeja, 5., 2018, Salvador, BA. Anais [...]. UFRGS, Porto Alegre, RS, 2018, p.70-76. Disponível em:

https://drive.google.com/drive/search?q=Os\%20egressos/estudante s\%20da\%20EJA\%20do\%20Ensino\%20m\%C3\%A9dio\%20e\%20o\%20a cesso\%20\%C3\%A0\%20Universidade:\%20an\%C3\%A1lise\%20dos\%20 microdados\%20do\%20ENEM . Acesso em: 10 set. 2021.

ARAÚJO, Adálcio Carvalho de. Egressos da EJA no Curso de Administração Pública EAD/FaPP/UEMG: uma análise dos fatores motivacionais da interrupção e retomada das trajetórias escolares e a continuidade dos estudos em nível superior na EAD. 2016. 174 f. Dissertação (Mestrado em Educação) - Faculdade de Educação, Universidade do Estado de Minas Gerais, Belo Horizonte, 2016. Disponível em: http://mestrados.uemg.br/ppgeducproducao/dissertacoes-ppgeduc/category/1172016? download = 547:egressos-da-eja-no-curso-de-administracaopublica-ead-fapp-uemg-uma-analise-dos-fatores-motivacionais-dainterrupcao-e-retomada-das-trajetorias-escolares-e-acontinuidade-dos-estudos-em-nivel-superior-na-ead. Acesso em: 3 jul. 2021.

ARROYO, Miguel. Gonzáles. Outros sujeitos outras Pedagogias. Petrópolis, RJ: Vozes, 2012.

BERTOLDI, Adriana Barufaldi. Aprendizagem de estudantes jovens e adultos: um estudo em cursos de educação profissional de nível médio e superior. 2008. 75 f. Dissertação (Mestrado em Educação) Universidade do Vale do Itajaí, Itajaí, 2008. Disponível em: 
http://siaibib01.univali.br/pdf/Adriana\%20Barufaldi\%20Bertoldi.pdf. Acesso em: 7 jul. 2021.

BISINELLA, Patrícia Borges Gomes. Trajetórias de Egressos da EJA na Transição para o Ensino Superior: um estudo a partir do Prouni (Caxias do Sul 2005 - 2014). 2016. 130 f. Dissertação (Mestrado em Educação) - Faculdade de Educação, Universidade de Caxias do Sul, Caxias do Sul, 2016. Disponível em:

https://editorarealize.com.br/artigo /visualizar/38698. Acesso em: 7 jul. 2021.

BISPO, Francineide de Sousa; LIRA, João Antônio de Sousa.

Trajetórias de egressos da EJA no ensino superior: desafios e perspectivas. In: IV Congresso Nacional de Educação. A Educação brasileira: desafios na atualidade, 4, 2017, João Pessoa - PB. Anais [...] João Pessoa - PB, 15 a 18 de novembro de 2017. Disponível em: https://editorarealize.com.br

/editora/anais/conedu/2017/TRABALHO_EV073_MD4_SA12_ID5527_ 11092017081047.pdf. Acesso em: 7 jul. 2021.

BOURDIEU, Pierre. Coisas Ditas. Tradução Cássia R. da Silveira e Denise Moreno Pegorim. São Paulo: Brasiliense, 2004.

BOURDIEU, Pierre. Razões práticas: sobre a teoria da ação Campinas, SP: Papirus. 1997.

CAMINHA, Ivanete Saskoski. Contribuições da EAD para o ensino superior presencial na visão de alunos egressos da educação de jovens e adultos. 2011. 120 f. Dissertação (Mestrado em Gestão e Desenvolvimento Regional) - Faculdade de Administração, Universidade de Taubaté, Taubaté, 2011. Disponível em:

http://bdtd.ibict.br/vufind/

Record/UNITAU_06edc32554300aa99d1922197a9b5618. Acesso em: 11 jul. 2021.

CHARLOT, Bernard. Da relação com o saber: elementos para uma teoria. Porto Alegre: Artes Médicas, 2000. 
CRUZ, Neilton Castro da. EITERER, Carmem Lúcia. A Inserção de Egresso/a da EJA no Ensino Superior Público na Bahia: a significativa contribuição do/a professor/a da educação básica na trajetória escolar desse sujeito. In: XVIII ENDIPE, 18., 2016, Cuiabá. Anais [...]. Cuiabá: Universidade Federal do Mato Grosso, 23 a 26 de agosto de 2016a.

CRUZ, Neilton Castro da. "Esse ambiente não é para todo mundo": as condições de inserção e de permanência de egressos/as da EJA no ensino superior público. 2016b. 203 f. Tese (Doutorado em Educação) - Faculdade de Educação, Universidade Federal de Minas Gerais, Belo Horizonte, 2016. Disponível em: https://repositorio.ufmg.br/handle/1843/BUOS-AQQRM6. Acesso em: 10 jul. 2021.

CRUZ, Neilton Castro da; EITERER, Carmem Lúcia. A Inserção de Egresso/a da EJA no Ensino Superior Público na Bahia: a significativa contribuição do/a professor/a da educação básica na trajetória escolar desse sujeito. In: ENCONTRO NACIONAL DE DIDÁTICA E PRÁTICAS DE ENSINO, 18., 2016, Cuiabá-MT. Anais [...] Cuiabá-MT, UFMG, 23 a 26 de agosto de 2016. Disponível em: https://1library.org/document/qmv76n8q-xviii-endipe-didatica-epratica-de-ensino-no-contexto-politico-contemporaneo-cenas-daeducacao-brasileira.html. Acesso em: 15 jul. 2021.

CRUZ, Neilton Castro da; REIS, Sônia Maria Alves de Oliveira. "Vim da EJA com muito orgulho". A inserção de egressos da Educação de Jovens e Adultos na Universidade do Estado da Bahia. In:

ENCONTRO NACIONAL DE DIDÁTICA E PRÁTICAS DE ENSINO, 19, 2018, Salvador, BA. Anais [...] Salvador, 2018.

DIAS, Alder de Sousa et al. Mulheres egressas da EJA na universidade: entre intempéries, sonhos possíveis e inéditos viáveis.

Revista Atos de Pesquisa em Educação. Blumenau, v. 11, n. 2, p.444-467, ago./nov. 2016. Disponível em: https://proxy.furb.br/ojs/index.php/ atosdepesquisa/article/view/5435. Acesso em: 10 jul. 2021. 
DOTTA, Carla Luz Salaibb. Da Educação Básica a Universidade: alunos da LEDOC oriundos da EJA. 2018. 78 f. Monografia (Graduação em Educação do Campo) - Universidade Federal do Rio Grande do Sul, Tramandaí, 2018. Disponível em: https://lume.ufrgs.br/handle/10183/181651. Acesso em: 10 jul. 2021.

FREIRE, Paulo. Pedagogia da Autonomia: Saberes necessários à prática educativa. 12. ed. São Paulo: Paz e Terra, 1999.

FREITAS, Adnilsa Avelino de. O Sucesso do Aluno da EJA e seu Ingresso no Ensino Superior. 2017. 54 f. Monografia (Graduação em Pedagogia) - Universidade do Estado do Rio Grande do Norte, 2017.

GADOTTI, Moacir. Qualidade na educação: uma nova abordagem. São Paulo: Instituto Paulo Freire, 2003

GENTILI, P. Escola S. A. Quem ganha e quem perde no mercado educacional do neoliberalismo. São Paulo: CNTE, 1999.

JESUS FILHO, Rubem Teixeira de. Contrariando a sina - da educação de jovens e adultos ao ensino superior: escolaridades exitosas de alunas trabalhadoras. 2013. 131 f. Dissertação (Mestrado em Educação) - Faculdade de Educação, Universidade Federal de Goiás, Goiânia, 2013. Disponível em: https://repositorio.bc.ufg.br/tede/handle/tde/2914. Acesso em: 10 jul. 2021.

LAHIRE, Bernard. Homem Plural: os determinantes da ação; Tradução de Jaime A. Clasen. Petrópolis, RJ: Vozes, 2002.

LAHIRE, Bernard. Sucesso Escolar nos meios populares: as razões do improvável. Tradução de Ramon Américo Vasques e Sonia Goldefeder. São Paulo: Ática, 2004.

MARQUES, Ramiro. Dicionário breve de Pedagogia. 2. ed. [S.I.], 2000. Disponível em dicionário\%20pedagogia.pdf> Acesso em: 15 mar. 2017.

MARTUCCELLI, Danilo. Suporte (Cap. I). In: MARTUCCELLI, Danilo. Gramáticas del indivíduo. Buenos Aires: Losada, 2007, p. 37-117. 
MUNIZ, Roberta de Jesus; REIS, Sônia Maria Alves de Oliveira. A Travessia da Educação de Jovens e Adultos para a Universidade: as Razões do Improvável - Painel Da EJA e do campo: os novos sujeitos na educação superior. novas didáticas? In: ENCONTRO NACIONAL DE DIDÁTICA E PRÁTICAS DE ENSINO, 19. UFBA, 2018, Salvador, BA. Anais [...] Salvador, $2018^{a}$, p. 2-13. Disponível em: http://www.xixendipe.ufba.br/modulos/consulta\&relatorio/rel_downl oad.asp?nome=99827.pdf . Acesso em: 10 set. 2021.

MUNIZ, Roberta de Jesus; REIS, Sônia Maria Alves de Oliveira. Da EJA para a universidade: o compasso entre o acesso e as singularidades dos sujeitos. In: ENCONTRO INTERNACIONAL DE ALFABETIZAÇÃO DE JOVENS E ADULTOS - Alfaeeja, 5., 2018, Salvador, BA. Anais [...] Uneb, Salvador, BA, 2018b. p.31- 37. Disponível em: https://drive.google.com/drive/u/0/folders/1IFBcO3VgboWkf9PWXA PRBjVIp8SxKfFb. Acesso em: 10 set. 2021.

NASCIMENTO, Maria Oliveira Rogirlene do. Inclusão dos estudantes da educação de jovens e adultos no ensino superior: desafios e percepções. In: CONGRESSO INTERNACIONAL DE EDUCAÇÃO INCLUSIVA - CINTEDI E JORNADA CHILENA BRASILEIRA SOBRE EDUCAÇÃO INCLUSIVA, 2., 2016, Campina Grande-PB. Anais [...] Campina Grande-PB, 16 a 18 de novembro de 2016. Disponível em http://editorarealize.com.br/editora/anais/cintedi/2016/TRABALHO_ EV060_MD1_SA14_ID2422_06102016155031.pdf. Acesso em: 10 jul. 2021.

NERES, Celi Corrêa; MILAN, Elizonir Ferreira Arcanjo; SILVA, Maria Lourdes S. Alunos da Educação de Jovens e Adultos: a recente trilha para a educação superior. Plurais - Revista Multidisciplinar, Salvador, v. 1, n. 2, p. 44-57, abr./ago. 2016. Disponível em: https://www.revistas.uneb.br/index.php/plurais/article/view/2678/18 10. Acesso em: 10 jul. 2021. 
PAZ, Sebastiana; SANTOS, Maria de Lourdes dos. O Ingresso de Alunos Egressos da EJA no Curso de pedagogia da UFGD - Turma de 2013. In: ENCONTRO DE ENSINO, PESQUISA E EXTENSÃO da UFGD e UEMS, 8., 5., 2014, Dourados-MS, 2014. Anais [...] Dourados-MS, 20 a 24 de outubro de 2014.

PEREIRA, Diego Rodrigo. Trajetórias escolares, condições de ingresso, permanência e conclusão dos egressos da educação de jovens e adultos na educação superior. 2018. 118 f. Dissertação (Mestrado em Educação) - Universidade Federal do Maranhão, São Luís, 2018.

PORTES, Écio Antônio. Trajetórias e estratégias do universitário das camadas populares. 1993. 248 f. Dissertação (Mestrado em Educação) - Faculdade de Educação, Universidade Federal de Minas Gerais, Belo Horizonte, 1993.

PORTES, Écio Antônio. Trajetórias escolares e vida acadêmica do estudante pobre na UFMG: um estudo a partir de cinco casos. 2001. 267 f. Tese (Doutorado em Educação) - Faculdade de Educação, Universidade Federal de Minas Gerais, Belo Horizonte, 2001.

ROMANOWSKI, Joana Paulin; ENS, Romilda Teodora. As pesquisas denominadas do tipo "estado da arte" em educação. Diálogo Educacional, v. 6, n. 19, p. 37-50, 2006. Disponível em: https://periodicos.pucpr.br/index.php/dialogoeducacional/article/vie w/24176. Acesso em: 10 jul. 2021.

ROSA, Caroline de Moura; SANT'ANNA, Sita Mara Lopes; STRAMARE, Odilon Antônio. Sentido de qualidade: Vozes de professores e estudantes egressos da EJA no Ensino Superior. Revista de Educação Pública, v.15, 2018. Disponível em: https://periodicoscientificos.ufmt.br/ojs/index.php/educacaopublica /article/view/7038. Acesso em: 10 jul. 2021.

SANTOS, Cintya Roberta Oliveira dos. Os sentidos sobre Universidade Pública para estudantes cotistas egressos da Educação de Jovens e Adultos: o contexto da Faculdade de 
Formação de Professores / UERJ. Dissertação (Mestrado em Educação) - Universidade do Estado do Rio de Janeiro (UERJ), 2018a SANTOS, Cleonice Iracema Graciano dos. Sentidos e (re)significados do PROEJA na trajetória dos egressos inseridos no Ensino Superior. Dissertação (Mestrado em Educação) Instituto Politécnico do Porto. 2018b.

SANTOS, Geovânia Lúcia dos. Educação Superior ainda que Tardia: impactos e efeitos da educação superior entre adultos egressos da EJA. In: CONFERÊNCIA FORGES, 6, 2016, Campinas-SP. Anais [...] Campinas-SP, 28 a 30 de novembro de 2016. Disponível em: http://www.aforges.org/wp-content/uploads/2016/11/4-Geovaniados-Santos_Educac_a_o-superior-ainda-que-tardia.pdf. Acesso em: 10 jul. 2021.

SANTOS, Graciele Silva dos; MUNIZ, Roberta de Jesus Muniz. Travessias da Educação de Jovens e Adultos para o Ensino Superior: Percursos de vida e trajetórias de formação. 2018. Trabalho de Conclusão de Curso (Graduação em Pedagogia) Departamento de Educação, DEDC Campus XII, Uneb, Guanambi, 2018.

SATO, Silvana Rodrigues de. Movimentos de democratização do acesso: análise do perfil dos inscritos e classificados à Universidade Federal de Santa Catarina em perspectiva longitudinal (2001-2015). 2018. 266f. Dissertação (Mestrado em Educação) - Universidade Federal de Santa Catarina, - UFSC, Florianópolis, 2018. Disponível em:

https://repositorio.ufsc.br/bitstream/handle/123456789/198638/PEE D1341-T.pdf?sequence=-1\&isAllowed=y. Acesso em: 10 jul. 2021.

SILVA FILHO, Raimundo Barbosa; ARAÚJO, Ronaldo Marcos de Lima Araújo. Evasão e abandono escolar na educação básica no Brasil: fatores, causas e possíveis consequências. Educação Por Escrito, Porto Alegre, v. 8, n. 1, p. 35-48, jan./jun. 2017. Disponível em: https://revistaseletronicas.pucrs.br/ojs/index.php/porescrito/article/v iew/24527. Acesso em: 10 jul. 2021. 
SILVA, Neilton da. Processo de afiliação de egressos da EJA no Ensino Superior: desafios e propostas à docência universitária. Revista Brasileira de Educação de Jovens e Adultos, v. 3, n. 5, p. 121-147, 2015. Disponível em:

https://www.revistas.uneb.br/index.php/educajovenseadultos/article /view/1389. Acesso em: 10 jul. 2021.

Submetido em: Julho/ 2021.

Aceito em: Agosto/ 2021. 